\title{
Review on Thermal Analysis of Solar Parabolic Collector by using CFD
}

\author{
Vicky Kumar \\ M. Tech Scholar \\ Truba Institute of Engineering and \\ Information Technology \\ Bhopal, MP, India \\ vickykumarsingh9216@gmail.com
}

\author{
Dr. Rajeev Arya \\ Director \\ Truba Institute of Engineering and \\ Information Technology \\ Bhopal, MP, India \\ rajeev.arya@trubainstitute.ac.in
}

\author{
Shravan Vishwakarma \\ Professor \\ Truba Institute of Engineering and \\ Information Technology \\ Bhopal, MP, India \\ shravanmits@gmail.com
}

\begin{abstract}
Solar energy is one of the most freely available forms of clean renewable energy. Many technologies have been developed in India to obtain energy from various renewable energies, but obtaining maximum thermal energy from solar energy is the most promising challenge. This article introduces solar energy and the solar energy collector. The introduction of the parabolic by the collector is also described.
\end{abstract}

Keywords: Renewable, Parabolic Collector, Solar Power Plants, Solar Energy.

\section{INTRODUCTION}

Many countries have now started using renewable energy due to increased energy needs and a lack of non-reusable energy used in refrigeration, air and water heating, large and small industry, desalination and power generation. In addition, the demand for fresh water will increase due to climate change, population growth and improved living standards. Solar power is the most readily available abundant energy source on earth for home lighting, thermal power generation, and industrial heating applications. Many countries with strong solar radiation such as Egypt, India, Mexico, Morocco and the United States are focusing on solar power for electricity. In the 1980s, 9 PTC systems were built in the Mojave Desert [1]. The fuel used in the desalination process is limited, costs and air pollution have increased. The distillation of fresh water from a solar still system is one of the best practical technologies implemented in several countries [2]. A solar collector can absorb solar radiation and convert it into thermal energy to convert water, air or oil into thermal energy. The thermal energy of the working fluid can be used directly for various applications. Solar collectors have different types such as parabolic collector (PTC), flat collector and composite parabolic collector (CPC). Flat collectors are generally used to produce hot water around $120-140{ }^{\circ} \mathrm{C}$ due to their temperature range. The temperature of the $\mathrm{PTC}$ receiver tube can be up to $350-400{ }^{\circ} \mathrm{C}$ [3]; It can therefore be used as a steam generator for power plants and for the desalination process. A typical power plant typically requires huge fossil fuels, which result in high carbon dioxide (CO2) emissions. In this way, the utilization of accessible sustainable power sources will assist with decreasing the utilization and contamination of nonsustainable power sources. Because of the proficiency of the sun powered explanatory gatherer, which is exceptionally subject to the fixation proportion (C), and the higher warmth ingestion of the PTC contrasted with the level authority, this article centers around the PTC with a high temperature reach and high focus relationship.

\section{LITERATURE REVIEW}

Tarun Kumar at el. [4] the investment costs associated with concentrated solar power plants (CSPs) are relatively higher than with other renewable energy generation options. In order to make CSP systems more competitive, it is necessary to explore different ways to reduce the cost of capital of CSP systems by taking advantage of the latest developments in the field.

José Fredriksson at el. [5] This overview defines the state of the art for parabolic trough collectors and identifies concepts within the innovation requirements. These include increasing operating temperatures and overall power plant efficiency, as well as reducing solar field costs by eliminating components and reducing parasitic energy consumption. The study examines 34 collector concepts and classifies them according to their most important structural characteristics such as mechanisms or materials. The results show that collectors operating with molten salts rather than diathermic oil have significant technical-economic potential for large-scale applications such as molten salt, the definitive reservoir and SkyFuelDSP (Shippable Solar Energy) as a precursor of their respective categories. The results also show that the Heliovis inflatable collector fueled with diathermic oil has significant economic potential.

Sanaz Akbarzadeh et al. [6] parabolic vacuum collectors (PTCs) are often used to generate thermal energy. Considerable attention is paid to improving the thermal performance of the PTCs. Corrugated pipes are widely used in engineering applications that manage to increase heat transfer and reduce system size. Despite the high efficiency of helical corrugated tubes, little work has been done to determine their 
efficiency in a PTC. Therefore, this experimental study examines the effects of corrugated pipes at different pitch ratios on PTC performance. Results show that PTC using corrugated tubing has the highest performance in the transition regime. The maximum increase in the Nusselt index was 4.2 with a split ratio of 0.12 and a roughness height ratio of 0.06 . The thermal power factor also increases by approximately $26 \%-176 \%$.

Meriem CHAANAOUI at el. [7] this study presents an exploratory investigation of a model for drying phosphate muck utilizing PTC (Parabolic Trough Collector) sun based innovation as a fuel source. It portrays the association of the three framework parts, to be specific the PTC circuit, the oilair heat exchanger $(\mathrm{HX})$ and the rotational dryer. The last influences the last dampness estimation of the mud. During the bright day, $32 \mathrm{~kg}$ of mud was dried for the duration of the day to the ideal dampness content with a generally steady temperature $\left(130 \pm 4{ }^{\circ} \mathrm{C}\right)$. This sum dropped to $7 \mathrm{~kg}$ on a shady day, while the objective dampness content was just $25 \%$ of the drying time. A reinforcement power source or warmth stockpiling framework is prescribed to improve drying execution in cloudy weather.

Amir Mohammad Norouzi et al. [8] In conventional parabolic solar collectors (PTCs), solar radiation is concentrated in the lower part of the absorber tube, causing high surface temperatures, thermal stresses and deformations with consequent damage and costs. The results show that selecting the optimum speed allows the absorber temperature to be reduced and controlled by approximately $60 \%$ of the fluid line temperature difference and $15 \%$ of the maximum surface temperature. In addition, the efficiency of the PTC has increased by approximately $17 \%$. The contribution of forces of natural forced convection, rotation and mass flux to the total heat transfer is analyzed by $\mathrm{Gr}, \mathrm{Re}$, Ta and a convection rating parameter (CEP).

\section{OVER VIEW ON NeEd OF SOlar POWER GENERATION}

The two main advantages of solar energy are that its fuel costs are absolutely zero and that the production of solar energy during its application does not come from greenhouse gases. Another advantage of using solar energy to generate electricity is its poor portability. We can do this when a little power generation is needed. The researcher is constantly striving to improve solar panel manufacturing technology to improve efficiency. This will certainly help make solar technology suitable for use in everyday life as a primary source of renewable energy [www.eai.in].

Solar energy is prevalent both on earth and in space, so we can get its energy and convert it to our relevant type of energy and use it consistently with the efficiency of electricity from solar energy, which depends on utility, from the location of the loading space the availability of the nearby electricity grid.
Even if the availability of grids for connection is very difficult or expensive, solar energy can be used to supply energy to these areas [www.eai.in].

\section{SOLAR ENERGY}

Solar energy is a type of unconventional energy source that uses solar radiation to generate electricity or for other domestic and industrial purposes. It is a renewable energy source, also called green energy. Because the rapid development of renewable energy technologies has a global impact on the environment and society. Some renewable energy sources emit very low carbon emissions and also help reduce global warming. It also reduces air pollution and contributes to social and economic development by creating jobs in rural and urban areas.

A. Application of solar energy

Solar energy has wide variety of applications which are classified as follows:

- Urban planning and architecture

- Horticulture and agriculture

- Steam Cooking/ Heating

- Process Heating

- Cooling and refrigeration

- Desalination of water

- Power/ Electricity generation

Solar energy is a fantastic source for meeting our electricity needs. Solar photovoltaic (photovoltaic) have the ability to convert incident solar radiation directly into electricity. This energy can be harnessed with photovoltaic cells and stored with a battery that can be used as needed. These can be used for such purposes:

- Village electrification

- Water pumping

- Street lighting

- Domestic lighting

- Mini grid

\section{SOLAR ENERGY COLLECTORS}

The purpose of a solar energy collector is to gather the radiant energy falling on its surface and then transfer this energy to fluid which is in contact with the collecting surface. These are classified as:

- Concentrating

- Non-concentrating

The basic difference between these is that of the absorber area. In a non-concentrating collector absorber area is nearly same as that the recipient area but on the other hand the energy falling on a large recipient area is focused on a small absorber area.

\section{INTRODUCTION OF PARABOLIC THROUGH} COLLECTOR 
A parabolic trough is a type of solar thermal collector that is straight in one dimension and curved like a parabola in the other two dimensions and is covered with a shiny metallic mirror. Sunlight entering the mirror parallel to its plane of symmetry is focused along the focal lines where objects are positioned to be heated. For example, food can be placed on the focal line of a well that cooks food if the well is oriented so that the sun is in its plane of symmetry. For more information on using parabolic drinkers for cooking, see the article on solar cookers.

For other purposes, there is often a tube, often a tube, running along the cavity at its focal line. The mirror is oriented so that the reflected sunlight is focused on the tube, which contains a liquid heated to a high temperature by the energy of sunlight. Hot liquid can be used for many purposes. It is often powered by a heat engine that uses heat energy to power machines or generate electricity.

\section{THERMAL EFFICIENCY OF THE PARABOLIC SOLAR} COLLECTOR

A brief overview of PTC thermal analysis is presented below. One among the most components of solar PTC to enhance efficiency is that the solar tracking system. The solar tracker keeps the PTC within the direction of the sun all day to receive radiation. Michael and Eckhard developed two highperformance SPTCs with an optical concentration ratio of 82: 1 and an operating temperature of over $500^{\circ} \mathrm{C}$. They also performed a structure and finite element analysis (FEA) to research the geometry of the collector structure and eventually concluded with the results of a further annual thermal production of up to twenty more efficiency [9]. Bakos developed a two-axis solar tracking system for PTC and located that the simplest thermal efficiency and moving surface collector are $46.46 \%$ more efficient than the fixed surface [10]. Valan Arasu and Sornakumar developed a solar PTC supported fiber-reinforced plastic which resulted in improved thermal efficiency and also reduced costs. Jeter performed a performance analysis taking under consideration parameters like optical efficiency, absorbent concentration ratio and concentrated flux . the development of the optical efficiency can only be done on the idea of the reflection, transmission and absorption properties of the collector [11]. Optimization studies are performed to enhance the heat transfer rate on the absorber tube with parameters like the diameter, length and flow of the heat transfer fluid and therefore the intensity of the incident radiation [12]. Parametric analysis shows the development of construction properties like absorber emission and influences of absorption on sensor efficiency [13]. Lobon et al. reported on the behavior of direct steam generation taking under consideration water as a working fluid by comparing the CFD (Computational Fluid Dynamics) analysis using the STAR CMMp package to the experimental result, which shows a far better thermal performance with a really coldness fluctuation of about $3{ }^{\circ} \mathrm{C}$ and pressure drops of $0.02 \mathrm{MPa}$ at the most [14] - [15]. Sie et al. Flux and heat transfer analysis performed employing a finite difference method and validation with experimental results shows a far better temperature range of over $300{ }^{\circ} \mathrm{C}$, which directly improves efficiency [16]. Risi et al. have developed an innovative transparent SPTC that works with gas-based nanofluids. The simulation shows a thermal efficiency of $62.5 \%$. They also reported that the temperature of the nanofluid was around $650^{\circ} \mathrm{C}[17]$.

\section{CONCLUSION}

This paper introduces solar energy and the solar energy collector. The introduction of the parabolic by the collector is also described. From the above literature, it appears that some researchers increase the parabolic antenna performance by manipulating its geometry and manufacturing techniques. Some of them improve their performance through the use of solar tracking mechanisms. Some of them have focused their research on the receiver design.

\section{REFERENCES}

[1] García-Cortés S, Bello-García A, Ordóñez C. Estimating intercept factor of a para-bolic solar trough collector with new supporting structure using off-the shelf photogrammetric equipment. Appl Energy 2012;92:815-21.

[2] Rajaseenivasan T, Elango T, Kalidasa Murugavel K. Comparative study of doublebasin and single basin solar stills. Desalination 2013;309:27-31.

[3] Pytilinski JT. Solar energy installations for pumping irrigation water. Sol Energy1978;21:255-62.

[4] Tarun Kumar at el. "Cost reduction potential in parabolic trough collector based CSP plants: A case study for India" Renewable and Sustainable Energy Reviews, Volume 138, March 2021, 110658. https://doi.org/10.1016/j.rser.2020.110658

[5] José Fredriksson, Martin Eickhoff, Lutz Giese \& Michael Herzog "A comparison and evaluation of innovative parabolic trough collector concepts for largescale application" Solar Energy, Volume 215, February 2021, Pages 266-310. https://doi.org/10.1016/j.solener.2020.12.017

[6] Sanaz Akbarzadeh \& Mohammad Sadegh Valipour "The thermo-hydraulic performance of a parabolic trough collector with helically corrugated tube" Sustainable Energy Technologies and Assessments, Volume 44, April 2021, 101013. https://doi.org/10.1016/j.seta.2021.101013.

[7] Meriem CHAANAOUI, Souad ABDERAFI, Sébastien VAUDREUIL\& Tijani BOUNAHMIDI "Prototype of phosphate sludge rotary dryer coupled to a parabolic trough collector solar loop: Integration and experimental 
analysis" Solar Energy, Volume 216, 1 March 2021, Pages 365-376. https://doi.org/10.1016/j.solener.2021.01.040

[8] Amir Mohammad Norouzi, Majid Siavashi, Rouhollah Ahmadi \& MiladTahmasbi "Experimental study of a parabolic trough solar collector with rotating absorber tube" Renewable Energy, Volume 168, May 2021, Pages 734-749. https://doi.org/10.1016/j.renene.2020.12.088.

[9] Kalogirou SA. Solar thermal collectors and applications. Prog Energy Combust Sci 2004;30(3):231-95.

[10] Michael Geyer, Eckhard Lupfert. "Eurotrough-Parabolic trough collector developed for cost efficient solar power generation". In: Proceedings of the 11th international symposium on concentrating solar power and chemical energy technologies. 4-6 Sep., Zurich, Switzerland; 2002.

[11] Bakos George C. Design and construction of a two-axis Sun tracking system for parabolic trough collector (PTC) efficiency improvement. Renew Energy 2006;31:241121.

[12] Jeter Sheldon M. Analytical determination of the optical performance of practical parabolic trough collectors from design data. Sol Energy 1987;39:11- 21.

[13] Bakos GC, Ioannidis I, Tsagas NF, Seftelis I. Design, optimisation and conversion-efficiency determination of a line-focus parabolic-trough solarcollector. Appl Energy 2001;68:43-50.

[14] Silva R, Perez M, Fernandez-Garcia A. Modeling and co-simulation of a parabolic trough solar plant for industrial process heat. Appl Energy 2013;106:287-300.

[15] Lobon David H, Baglietto Emilio, Valenzuela Loreto, Zarza Eduardo. Modeling direct steam generation in solar collectors with multiphase CFD. Appl Energy 2014; 113:1338-48.

[16] You Changfu, Zhang Wei, Yin Zhiqiang. Modeling of fluid flow and heat transfer in a trough solar collector. Appl Therm Eng 2013;54:247-54.

[17] De Risi A, Milanese M, Laforgia D. Modelling and optimization of transparent parabolic trough collector based on gas-phase nanofluids. Renew Energy 2013;58:134-9. 